This is a postprint version of the following published document:

Olmos, D., Baselga, J., Mondragon, I. \&

González-Benito, J. (2008). The Effect of Surface Modification of Silica Microfillers in an Epoxy

Matrix on the Thermo-mechanical Properties.

Journal of Adhesion Science and Technology, 22 (13), pp. 1443-1459.

DOI: $10.1163 / 156856108 X 305750$

(C) Koninklijke Brill NV, Leiden, 2008

(C) Taylor \& Francis 


\title{
The Effect of Surface Modification of Silica Microfillers in an Epoxy Matrix on the Thermo- mechanical Properties
}

\author{
D. Olmos ${ }^{\text {a }}$, J. Baselga ${ }^{\text {a }}$, I. Mondragon ${ }^{\mathrm{b}}$ and J. González-Benito ${ }^{\mathrm{a}, *}$ \\ ${ }^{\text {a }}$ Instituto de C. Materiales y Química Álvaro Alonso Barba, Universidad Carlos III de Madrid, \\ Avda. Universidad 30, 28915, Leganés, Madrid, Spain \\ b Escuela Ingeniería Técnica Industrial, Departamento de Ingeniería Química y del M. Ambiente, \\ Universidad del País Vasco/Euskal Herriko Unibertsitatea, Avda. Felipe IV, 1 B, 20011, \\ San Sebastián/Donosita, Spain \\ * To whom correspondence should be addressed. Tel.: +34-91-624-88-70; Fax: +34-91-624-94-30;
}

\begin{abstract}
Thermo-mechanical and mechanical studies were carried out on silica filled epoxy composites. The ef-fects of the filler with and without surface modification were studied. Silica particles were incorporated into the polymer matrix: (i) as received and (ii) surface treated with aminosilane coupling agents, namely 3 -aminopropyltriethoxysilane (APTES) and 3-

aminopropylmethyldiethoxysilane (APDES). The epoxy ma-trix consisted of poly (bisphenol A-coepichlorohydrin) glycidyl end-capped (DGEBA) resin cured with ethylenediamine (EDA). The relaxation temperatures assigned to the glass transition temperatures $\left(T_{\mathrm{g}}\right)$ of the composites revealed that the filler both with and without surface treatment greatly affects the polymer network structure. It seems that on filling the epoxy-amine reactive mixture with silica a stoichiometric change

in the epoxy/amine mixture occurs, which causes a decrease in the $T_{\mathrm{g}}$. However, no significant differences were found for the different surface treatments. Assuming the systems were homogeneous a pseudo-fractional free volume was calculated from the superposition in the slow dynamics regime and good correlations between this parameter with the type of surface treatment and with the yield stress were found.
\end{abstract}

\section{Keywords}

Surface treatments, composites, epoxy, silica fillers

\section{Introduction}

The addition of fillers into polymers is crucial when specific material performance is required. They improve certain properties of the final material, minimize the shrink-age during cure, enhance stiffness, and reduce the cost of the material, which are greatly important in recent applications as electronic packaging $[1,2]$ and dental restoratives $[3,4]$. The incorporation of reinforcing particles in an epoxy matrix re- 
duces thermal stresses in packaging [1], increases its elastic modulus as well as the yield stress $[5,6]$. There are several variables that greatly affect the curing behaviour of the filled composites. Bajaj et al. [7] observed acceleration of the epoxy-amine cure, especially at high loading of mica particles and a slight reduction in the glass transition temperature, $T_{\mathrm{g}}$, of the fully cured epoxy resin as the mica content was increased. The first point was explained in terms of the accelerating effect by the acidic surface silanol groups. The second observation was attributed to the reduction in crosslink density due to the presence of mica in the network but no mechanistic explanation was provided. The same conclusion was reached by Altmann et al. [8], who studied the effects of silica filler on the cure properties of an epoxy/amine sys-tem. They observed that at high cure temperatures $\left(100^{\circ} \mathrm{C}\right.$ and above) there seemed to be no effect of fillers on the cure kinetics nor on the gelation and vitrification times. However, at low curing temperatures $\left(60-90^{\circ} \mathrm{C}\right)$ the reaction rate increased and the gelation and vitrification times decreased with increasing filler content. An explanation for these results was given in similar terms, i.e. catalytic effect of hy-drogen donor species present on the silica surface on the epoxy/amine addition reaction. On the other hand, the effects of volume fraction and size of the filler on fracture behaviour have been studied [6] and it was found that: (i) as the volume fraction increases, the fracture toughness of composites (either critical stress inten-sity factor or strain energy release rate) increases; (ii) the incremental toughening effect diminishes with increasing volume fraction and (iii) generally larger particle filled epoxies were slightly tougher than smaller particle filled epoxies, but the size effect was found to be of secondary influence on fracture toughness, except when nanofillers were used. In these cases very high fracture toughness can be reached when the fracture mechanism entails crack propagation around the edge of the parti-cle. Furthermore, it is well known that the reinforcing potential of a filler is greatly dependent on the quality of its dispersion in the matrix [9, 10], and the particle size and agglomeration distribution affect the rheological properties of the polymer composite system [11]. Thus, it is crucial to characterize the extent of dispersion. Moreover, the enhancement in the properties of these composites is usually related to the quality of the adhesion between the reinforcement component and the matrix. Therefore, it is clear that there must be a close relation between these two aspects and it would be interesting to deal with them separately in order to understand the role of fillers in a composite material. It is well known that filler anisotropy, i.e. large "aspect ratio", is especially favourable in matrix reinforcements [12] although their limited commercial availability, dispersion problems due to the strong interparticle interactions, and anisotropic properties of these composites limit the applications of this kind of fillers [13].

The significant effects of the interface on the properties of particle reinforced composites have led to a considerable amount of effort to understand, control, and specifically to modify it. In general, surface treatments of particle reinforcements are common methods to improve the adhesion properties as well as hydrolytic stability by increasing electrostatic interactions and/or facilitating chemical bonding 
between the constituents [14]. Coupling agents have an important effect on the interfacial structure and properties [15]. Coupling agents have several functionalities that are designed to chemically bond both with the reinforcement and with the organic matrix. The most commonly used coupling agents are organosilicon compounds [16]. The silane coupling agents for most silica reinforcements (glass fibers, silica particles and quartz) have three hydrolysable alkoxy functional groups. These groups allow the silanes to react with each other and with the silanol groups of the silica surface to form multi-layer networks.

By using FT-IR imaging, González-Benito [17] observed that the chemical structure of an epoxy matrix changed gradually while approaching the reinforcement (glass fiber), due to a variation in epoxy conversion. This effect was attributed to a stoichiometric imbalance (off-stoichiometry) in the initial composition of the epoxide mixture (epoxy/amine) around the reinforcement. Furthermore, depending on the surface treatment of the reinforcement the characteristic length dimension of the influence of the reinforcement was modified. On the other hand, Van Assche and Van Mele [18], used micro-thermal analysis to observe spatial variations in the thermal properties of the interfacial region in an anhydride-cured epoxy system filled with porous silica particles. Correlation between microscopic properties at the interfacial level and the macroscopic behaviour of the whole system seems now to be essential for materials design of filled composites.

This work has focused on the characterization of a silica filled epoxy composite and the effects of the particle distribution and the surface treatment on the thermomechanical and mechanical properties of the composites.

\section{Experimental}

\subsection{Materials}

Silica particles SMF2, prepared according to the methods described in [19, 20], were supplied by Tolsa S. A. (Madrid, Spain) and used as reinforcement in an epoxy matrix. The $\mathrm{SiO}_{2}$ content was around $90 \%(\mathrm{w} / \mathrm{w})$, the specific surface area was $500 \mathrm{~m}^{2} / \mathrm{g}$ and the maximum water content was $1.5 \%(\mathrm{w} / \mathrm{w})$ [20] as checked by thermogravimetry. The silica particles were fibers with a length of $0.2-1.0 \mu \mathrm{m}$ arranged in bundles of about $50 \mathrm{~nm}$. The silica particles were used: (i) as received and (ii) surface coated with aminosilane coupling agents, namely 3-aminopropyltriethoxysilane (APTES) and 3-aminopropylmethyldiethoxysilane (APDES), both supplied by Sigma-Aldrich (Madrid, Spain). Poly (bisphenol Aco-epichlorohydrin) glycidyl end-capped (DGEBA) used as epoxy resin $\left(M_{\mathrm{n}}=\right.$ $348 \mathrm{~g} / \mathrm{mol}$ ) and ethylenediamine (EDA) used as a curing agent were both also supplied by Sigma-Aldrich.

\subsection{Sample Preparation}

As received silica particles $(1 \mathrm{~g})$ were introduced in a flask containing $50 \mathrm{ml}$ of a $2 \%(\mathrm{v} / \mathrm{v})$ silane aqueous solution for 15 minutes. In order to obtain different 
Table 1.

Sample code and sample preparation

\begin{tabular}{lll}
\hline Sample code & Filler & Treatment \\
\hline SILICA & Yes & No \\
APTES & Yes & APTES \\
APTES50 & Yes & APTES + APDES $(50 \%, \mathrm{v} / \mathrm{v})$ \\
APDES & Yes & APDES
\end{tabular}

coating chemical structures, three silane aqueous solutions were used: (i) APTES, (ii) APDES and (iii) APTES + APDES, 1:1 (w/w) (APTES50). After filtration, the adsorbed silane was heated at $110^{\circ} \mathrm{C}$ for $1 \mathrm{~h}$ to accelerate the siloxane condensation and to remove water, Soxhlet extracted for $4 \mathrm{~h}$, to remove any physisorbed silane residue and vacuum dried for at least $8 \mathrm{~h}$.

The epoxy resin was degassed, stoichiometrically mixed with the curing agent at room temperature and injected into a special mould to obtain specimens with $0.55 \mathrm{~mm}$ thickness. In order to prepare the composites, the silica particles were dispersed in the epoxy resin with a moderate stirring for $15 \mathrm{~min}$ before adding the curing agent, having finally a silica content of $20 \%$ (w/w). The composite materials were prepared by mixing the modified silica microparticles ( $\sim 20 \% \mathrm{wt})$ and the two components of the epoxy resin in a mould. The mould was prepared using two thick glass plates and placing a Teflon spacer between them. The system was then fixed with two steel frames joined together with a set of screws to exert pressure over the mould. Between the glass plates and the steel frames a set of silicone joints were placed to avoid the fracture of the glass. Finally, in order to prevent sticking, the glass plates surfaces were treated with a commercial mould release agent prior to composite preparation. The samples were cured at $60^{\circ} \mathrm{C}$ for $24 \mathrm{~h}$ and postcured at $110^{\circ} \mathrm{C}$ for $2 \mathrm{~h}$. In Table 1 the sample codes and preparation process for each sample are shown.

\subsection{Methods of Analysis}

(a) Fourier Transform Infrared (FT-IR) Spectroscopy.

The surfaces both coated and uncoated silica particles used were analyzed with a Perkin Elmer 16-PC FT-IR (Perkin-Elmer, Spain). A small portion of silica (neat or treated) was ground, diluted in $\mathrm{KBr}$ and moulded into a typical pellet for FTIR study in the transmission mode. As background, a $\mathrm{KBr}$ pellet was used and, in every analysis, $4 \mathrm{~cm}^{-1}$ resolution and 10 scans were selected as the instrumental conditions. Scan range was in the medium range, from 4000 to $400 \mathrm{~cm}^{-1}$.

(b) Thermogravimetric analysis (TGA).

A Setaram-92 thermobalance (Caluire, France) was used to determine the maximum amount of aminosilane deposited onto the silica particles. TGA analyses with temperature ranging from 30 to $700^{\circ} \mathrm{C}$ at a heating rate of $10^{\circ} \mathrm{C} / \mathrm{min}$ were carried 
out for the three kinds of silane coated silica particles. Samples (10-15 mg) were measured in a nitrogen gas atmosphere.

(c) Dynamic Mechanical Thermal Analysis (DMTA).

All samples prepared were analysed in a Perkin Elmer TAC 7/DX equipment (Perkin-Elmer, Spain) in the three-point bending mode. Two types of analyses were performed: (i) temperature scan from 40 to $200^{\circ} \mathrm{C}$ with the frequency fixed at $1 \mathrm{~Hz}$ and at a heating rate of $2^{\circ} \mathrm{C} / \mathrm{min}$, and (ii) frequency multiplex from 1 to $50 \mathrm{~Hz}$ at different constant temperatures. The instrumental conditions were set as follows, $80 \mathrm{mN}$ for the static force, $40 \mathrm{mN}$ for the dynamic force and $40 \mathrm{ml} / \mathrm{min}$ of $\mathrm{He}$ as the purge gas.

\section{(d) Mechanical testing.}

Evaluation of mechanical properties, i.e. flexural strength and flexural modulus, was performed using a Universal Testing Machine Instron 4202 (Instron, Spain). Flexural strength and flexural modulus were measured at room temperature by the three-point bending test. As a guide for performing and interpreting the tests, the ASTM D790 standard was followed, choosing the deformation rate of $1 \mathrm{~mm} / \mathrm{min}$. The specimens dimensions were $0.55 \times 10 \times 25 \mathrm{~mm}$ and a $14.5 \mathrm{~mm}$ span was selected.

(e) Scanning Electron Microscopy (SEM).

Fracture surfaces of the tested specimens were observed using a Philips XL30 scanning electron microscope, SEM (FEI Europe, Spain). The analysis of the silica particle size distribution was carried out using the "find features" mode of the Image-Pro Plus 3.0 software. All the samples were coated with $\mathrm{Au} / \mathrm{Pd}$ to avoid surface charge.

\section{Results and Discussion}

In Fig. 1 the FT-IR spectra for the coated and uncoated silica are presented. Because of the difficulty in assigning the bands due to their weak absorbances, a subtraction between the coated silica spectra and the uncoated silica spectrum was carried out (Fig. 2). Only small differences can be observed when the silica is treated with the silane solutions; therefore, only a few qualitative conclusions can be drawn: (i) the water content slightly decreases (broad band from 3800 to $3000 \mathrm{~cm}^{-1}$ ); (ii) the organic groups presence is confirmed by the $\mathrm{C}-\mathrm{H}$ stretching modes (3000-2800 $\mathrm{cm}^{-1}$ ) and (iii) as the $\mathrm{H}-\mathrm{N}-\mathrm{H}$ flexion mode reflects, there are free $\left(1600 \mathrm{~cm}^{-1}\right)$ and hydrogen bonded $\left(1550 \mathrm{~cm}^{-1}\right)$ amino groups (Fig. 2). The stretching modes assigned to protonated and non-protonated amino groups cannot be clearly analyzed because they are hidden within the broad band assigned to the water stretching modes $\left(3800-3000 \mathrm{~cm}^{-1}\right)$. These results are in accord with those obtained when glass fibers were coated with the same silanes [21-24]. Finally, it is observed that the amine content seems to follow the order: 


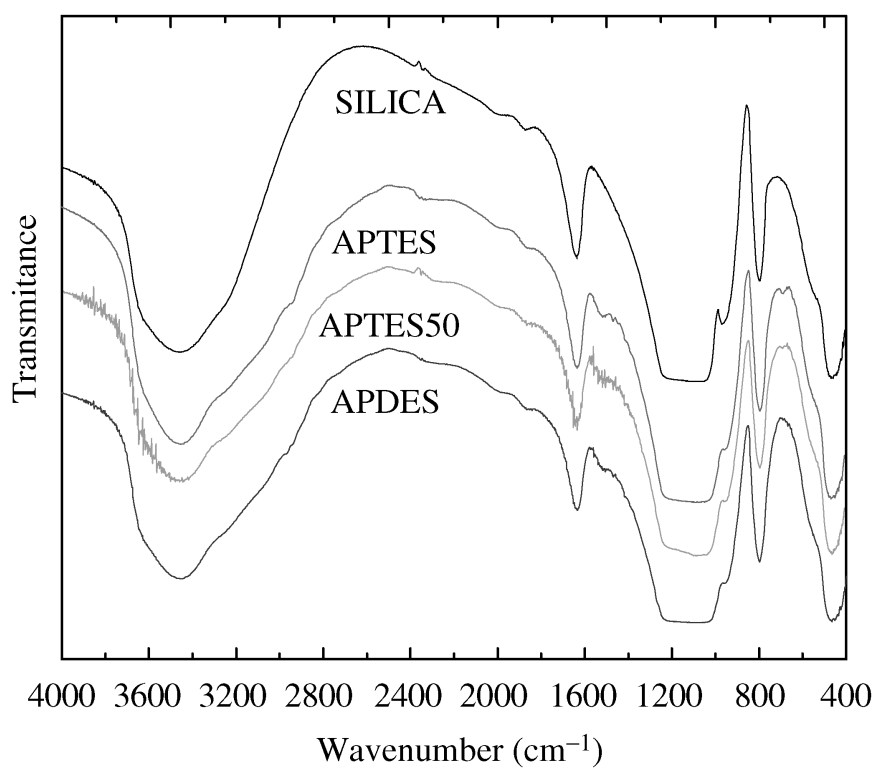

Figure 1. FT-IR spectra for the coated and uncoated silica.

APTES $>$ APTES50 $\geqslant$ APDES, which would reflect the same order in the amount of silane adsorbed on the silica surface.

Table 2 shows the most relevant data derived from the TGA experiments. The weight loss due to the silane coating was estimated from the interval of the thermograms for which the silane is thermally degraded $(300,450)^{\circ} \mathrm{C}$. Additionally, dehydroxylation reaction $(\mathrm{SiOH}+\mathrm{SiOH})$ can take place, because it happens at temperatures higher than $450^{\circ} \mathrm{C}$. The results shown in the table reflect that the amount of silane adsorbed by the reinforcement follows the same order as was obtained when the amount of silane was estimated from the FT-IR spectra, indicating a good agreement between these two techniques.

The dynamic-thermo-mechanical properties were measured by DMA from 40 to $200 \mathrm{~Hz}$. The relaxation temperature, $\alpha$-relaxation, which is considered as the glass transition temperature, $T_{\mathrm{g}}$, was determined as the temperature corresponding to the maximum in the loss modulus $E^{\prime \prime}$ (according to ASTM D 4065). The frequency was $1 \mathrm{~Hz}$ [25]. When considering the $T_{\mathrm{g}}$ as the temperature at which the loss factor, $\tan \delta$, presents a maximum, similar results were obtained. The height of the loss factor peak associated with the $\alpha$-relaxation $(\tan \delta)_{\max }$, is related to the segmental motion and the amount of relaxing species. The shape of the loss factor peak indicates homogeneity in the relaxation processes, while the width, $\omega$, is related to the temperature distribution for which the transition is activated. If the peak height rises, the width decreases and its integral, $(\tan \delta)_{\text {int }}$, increases. Then, the number of segments that acquire mobility at the same temperature also increases. In addition, the loss factor peak usually is more asymmetric when phase separation or strong interactions occur on adding a second component. 


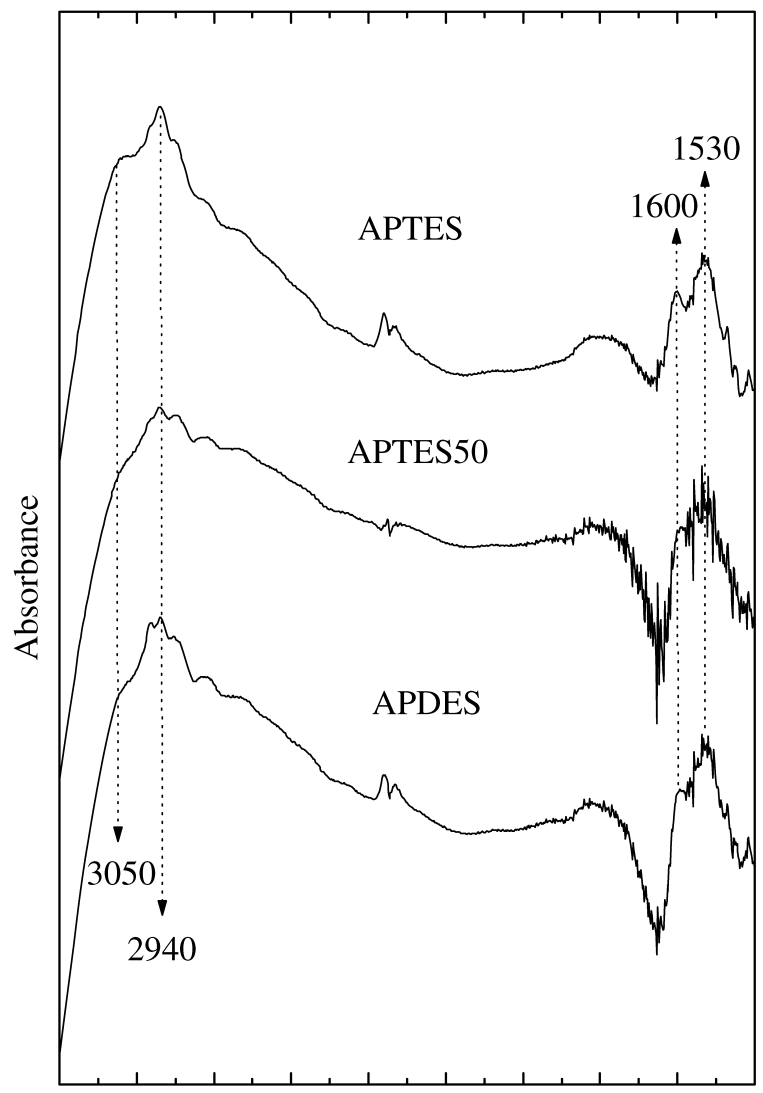

3200300028002600240022002000180016001400

Wavenumber $\left(\mathrm{cm}^{-1}\right)$

Figure 2. FT-IR spectra resulting from the subtraction between the coated silica spectra and the uncoated silica spectrum.

Table 2.

Weight loss of silane coating obtained from TGA experiments

\begin{tabular}{lll}
\hline Sample & Sample weight $(\mathrm{mg})$ & Weight loss of silane $(\%)$ \\
\hline APTES & 10.74 & 3.5 \\
APTES50 & 10.66 & 2.6 \\
APDES & 12.58 & 2.5 \\
\hline
\end{tabular}

The variations of the loss modulus and loss factor as a function of temperature are presented in Figs 3 and 4 respectively for all the samples under study. In Fig. 3 the different temperatures for the maximum in the loss modulus $\left(E^{\prime \prime}\right)$ are observed, indicating different $\alpha$-relaxation temperature values, $T_{\mathrm{g}}$, for each sample (Table 3 ). 


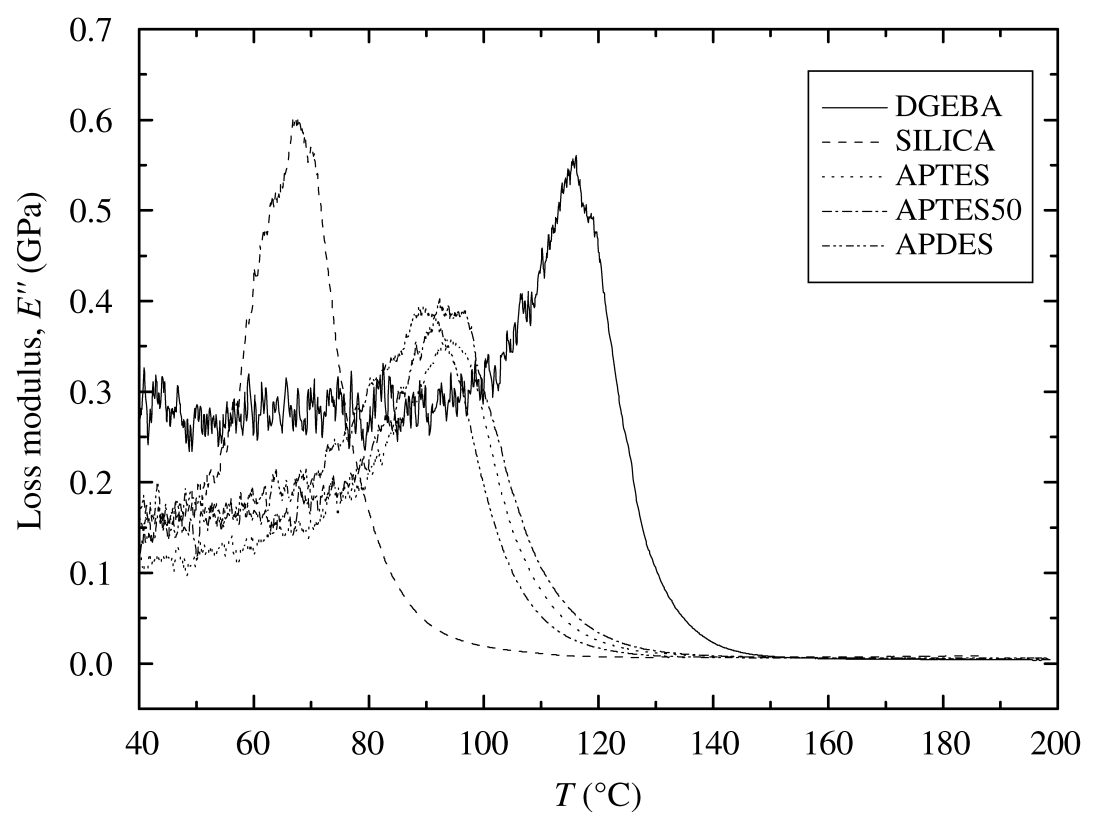

Figure 3. Loss modulus, $E^{\prime \prime}$, for all samples prepared, as a function of temperature.

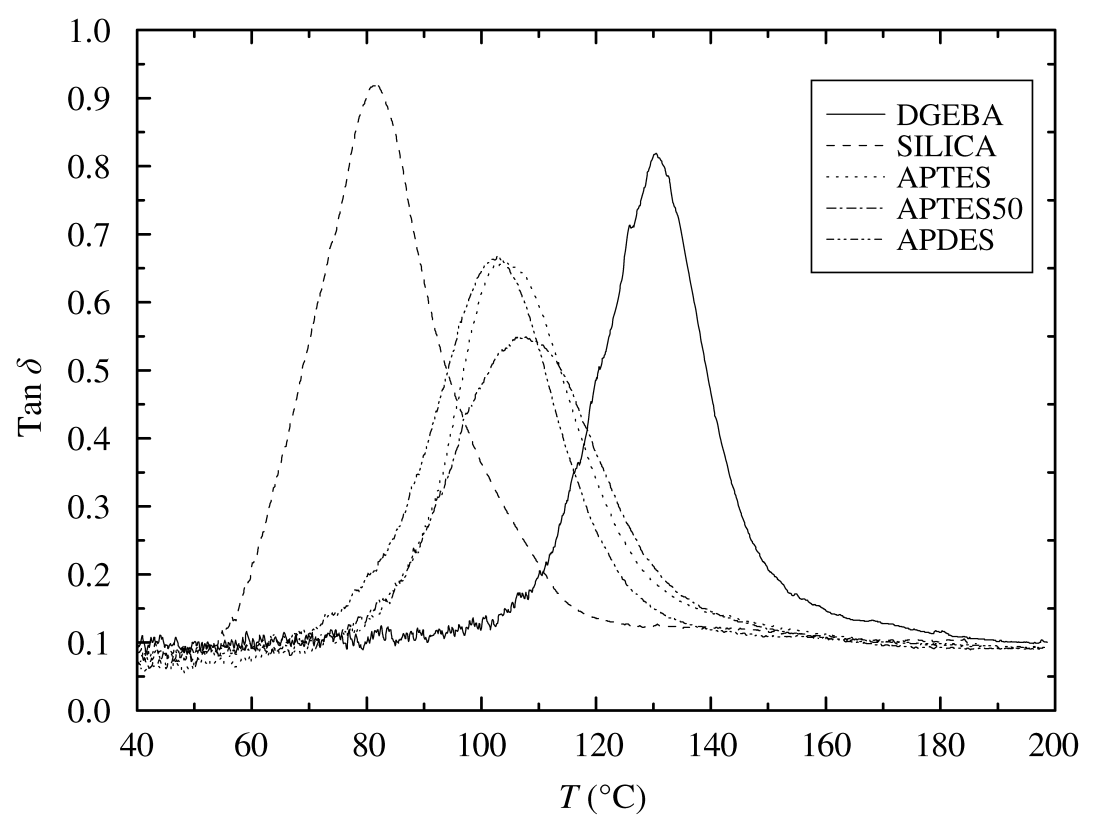

Figure 4. Loss factor, $\tan \delta$, for all samples prepared, as a function of temperature.

Considering that the same epoxy/amine ratio was used in all the samples, similar values of $T_{\mathrm{g}}$ should be expected, since similar polymer structures should be ob- 
Table 3.

Parameters obtained from the DMA curves

\begin{tabular}{lcllllll}
\hline Sample & $T_{\mathrm{g}}\left({ }^{\circ} \mathrm{C}\right)$ & $(\tan \delta)_{\max }$ & $(\tan \delta)_{\text {int }}$ & $\omega\left({ }^{\circ} \mathrm{C}\right)$ & $(\tan \delta)_{\max } / \omega$ & $E_{\text {rub }}^{\prime}(\mathrm{MPa})$ & $\chi$ \\
\hline DGEBA & 116 & 0.72 & 18.6 & 20.8 & 0,0346 & $37.4 \pm 0.8$ & - \\
SILICA & 68 & 0.85 & 26.3 & 25.3 & 0,0336 & $66 \pm 13$ & 1.8 \\
APTES & 94 & 0.58 & 19.0 & 25.2 & 0,0230 & $58 \pm 2$ & 1.4 \\
APTES50 & 93 & 0.47 & 17.2 & 30.9 & 0,0152 & $58 \pm 1$ & 1.4 \\
APDES & 89 & 0.58 & 17.9 & 25 & 0,0232 & $58 \pm 3$ & 1.4
\end{tabular}

$T_{\mathrm{g}}$ : glass transition temperature; $(\tan \delta)_{\max }$ : maximum value of $\tan \delta ;(\tan \delta)_{\text {int }}$ : integrated value of $\tan \delta$ and $\omega$ width of the $\tan \delta$ peak; $E_{\text {rub }}^{\prime}$ : rubbery modulus; $\chi$ : interaction parameter (Halpin-Tsai equation).

tained. However, the $T_{\mathrm{g}}$ values obtained reveal that the filler has a great effect on the polymer structure, at least under the curing conditions used in this work. This result is in accord with the findings of Bajaj et al. [7] in epoxy/mica composites. They observed a reduction in the $T_{\mathrm{g}}$ of the fully cured epoxy resin as the mica particles content increased but a complete explanation was not provided.

The reduction of the $T_{\mathrm{g}}$ in a filled epoxy system can be attributed, in principle, to three primary reasons: (i) an incomplete curing schedule; (ii) plasticization effect due to adsorbed water and (iii) an imbalance of stoichiometry. The first point can be neglected because curing can be reactivated during the DMA analysis inducing an increase of the storage modulus in the high temperature range and this has not been observed (Fig. 5). In addition, after a second temperature scan all the samples presented the same $T_{\mathrm{g}}$ values except the sample named Silica for which the $T_{\mathrm{g}}$ increased by $10^{\circ} \mathrm{C}$ but that was still lower than the $T_{\mathrm{g}}$ for the other samples.

With respect to the second point, it should be noted that water can only enter in the system via an inefficient drying process of the filler. Due to its high surface polarity, silica particles usually contain a strongly associated water layer over the surface and within its pores, and thus high temperatures are needed to remove it. Since the silica particles have been used in the "as received" state (see Experimental Section) and with the hypothesis that all the adsorbed water migrates through the matrix, the maximum amount of water that can enter the system is $0.3 \%$ (for the SILICA sample). This amount of water can be estimated considering that the water content of the silica is approximately $1.5 \%$ and taking into account that the silica represents $20 \%$ by weight of the composite sample. According to literature data, the change in the $T_{\mathrm{g}}$ that might be expected should be around $-10^{\circ} \mathrm{C}$ (for DGEBA/meta-phenylenediamine system) [26], less than $-5^{\circ} \mathrm{C}$ (for DGEBA/diamino diphenylmethane) [27] or even increase around $2^{\circ} \mathrm{C}$ (for DGEBA/piperidine/CTBN system) [28]. It becomes clear therefore that a water uptake of $0.3 \%$ cannot justify a decrease of $30-50^{\circ} \mathrm{C}$ in the $T_{\mathrm{g}}$; this second point should not be considered. 


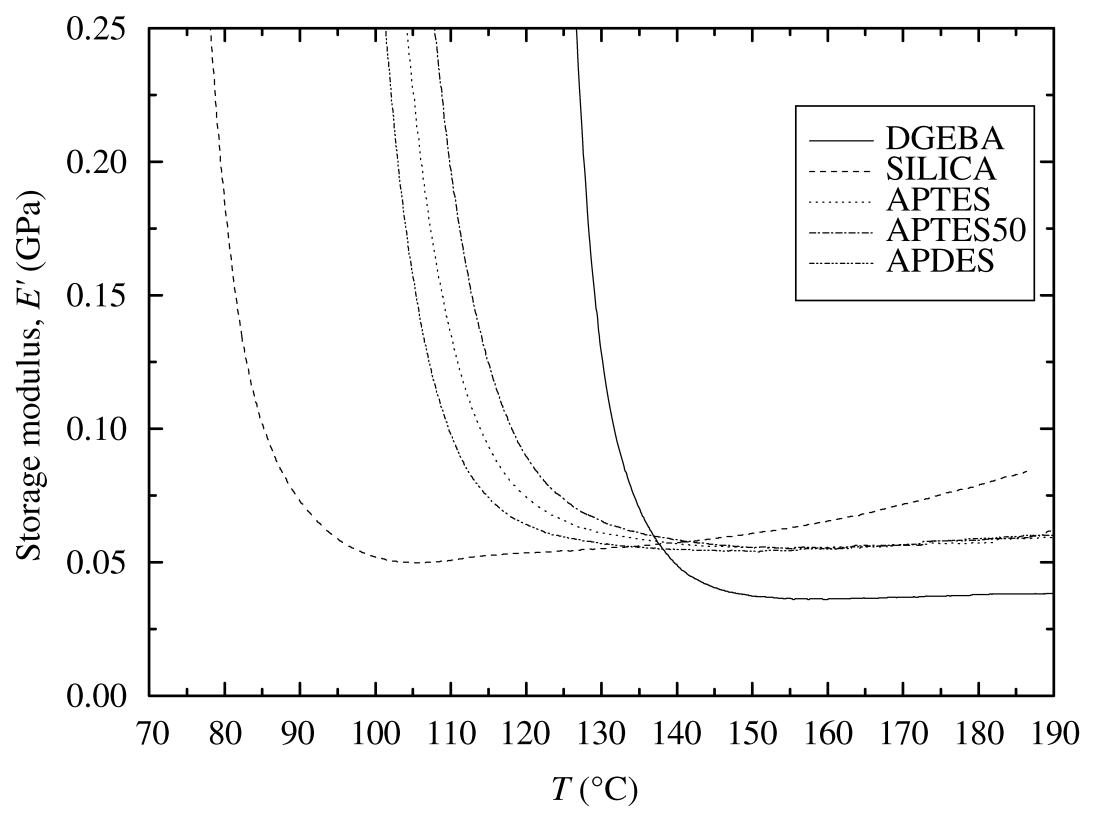

Figure 5. Storage modulus, $E^{\prime}$, versus temperature for the composites under study.

Using FT-IR imaging, a variation in the chemical structure of an epoxy matrix when approaching the reinforcement (glass fibre) has been recently reported for an epoxy/amine composite [17]. The phenomenon was attributed to a gradient in the composition of the epoxide mixture (epoxy/amine) near the filler surface. In that paper, it was suggested that the more the silanol groups are present on the surface of the filler, the more protonated amino groups exist and the larger the interphase with lower epoxy conversion is. This interpretation may help to understand some data from Table 3.

The SILICA sample, which was not coated with any silane, presents the highest surface free energy [24]; therefore, the effect of surface polarity on the composition of the matrix near the filler should be the highest. The lowest value of the $T_{\mathrm{g}}$ found for the untreated sample is in accord with this interpretation and reflects the very large influence of the filler surface free energy, at least at the filler contents used in this work $(20 \% \mathrm{w} / \mathrm{w})$. On the other hand, the $T_{\mathrm{g}}$ of the sample that has no filler, DGEBA, is the highest one and may be considered as an optimum value. In the other samples, the filler has been coated with different hydrophobic compositions, lowering the surface free energy; the off-stoichiometry induced by the filler surface should be lower, resulting in intermediate values of the $T_{\mathrm{g}}$. No significant differences are found for the different coating compositions.

Table 3 also presents the value of $\tan \delta$ at the maximum, $(\tan \delta)_{\max }$, the integrated value of $\tan \delta,(\tan \delta)_{\text {int }}$, and the width of the $\tan \delta$ peak, $\omega$ (in ${ }^{\circ} \mathrm{C}$ ) obtained from Fig. 4. The higher ratio $(\tan \delta)_{\max } / \omega$ corresponds to the neat epoxy matrix and untreated SILICA-filled samples, suggesting, as mentioned, that a greater segmental 
mobility and more relaxing species operate in these samples. In the case of neat epoxy matrix, the latter may be attributed to the higher concentration of the polymer, while for the SILICA sample it seems to be related to its more open structure at the interface level, since for this sample the highest off-stoichiometry exists. The other three samples would represent intermediate cases, with the sample APTES50 more heterogeneous, from the point of view of different types of relaxing species, because of its higher $\omega$ value. On the other hand, these results might be interpreted in terms of the quality of filler dispersion and the particles and/or aggregates shape, since they should affect the properties of the composite. However, in the case of the relaxation phenomena, these aspects should be related with the motions of the polymer influenced by differences in the mechanical coupling, internal stresses, etc. Thus, at least for the samples under study it is reasonable to consider that all of these aspects are mutually interconnected with each other and with the big changes of the interphases which, in fact, have been considered to be responsible for the results obtained.

Another interesting feature from Table 3 is related to the values of the rubbery modulus, $E_{\text {rub }}^{\prime}$ measured $50^{\circ} \mathrm{C}$ above the $T_{\mathrm{g}}$. The corresponding value for the neat epoxy matrix gives an average molecular weight between crosslinks [29-31] of about $320 \mathrm{~g} / \mathrm{mol}$, in good agreement with that expected for the fully cured system. The values corresponding to the filled systems are higher, reflecting the presence of particulates. In these composites, particles are aggregated and can be considered spherical-shaped as a first approximation. Assuming a shape factor $\xi=2$ for spherical-shape fillers [32], the reinforcing efficiency factor $\chi$ can be easily calculated using the well-known Halpin-Tsai semi-empirical relationship [32-34]:

$$
E_{\mathrm{C}}=E_{\mathrm{M}}\left(\frac{1+\xi \chi \phi_{\mathrm{F}}}{1-\chi \phi_{\mathrm{F}}}\right)
$$

where $E_{\mathrm{C}}, E_{\mathrm{M}}$ are the moduli of the composite and the matrix, respectively, and $\phi_{\mathrm{F}}$ is the volume fraction of the filler. To calculate the volume fraction of the filler, the density of the filler and the matrix were assumed to be $\rho_{\mathrm{F}}=2.3 \mathrm{~g} / \mathrm{cm}^{3}$ and $\rho_{\mathrm{M}}=1.18 \mathrm{~g} / \mathrm{cm}^{3}$, respectively. The values of $\chi$ [32] appear in the last column of Table 3. The "reinforcing efficiency" parameter is an arbitrary scaling parameter that indicates the extent to which the applied load is transmitted to the reinforcing phase. Taking into account the errors in the determination of $\chi$, all the studied samples present the same reinforcing efficiency at temperatures well above their $T_{\mathrm{g}}$. Due to this, the analysis of other experimental data should be done to ascertain the effect of the silane coating composition.

As it is common in highly crosslinked systems [25], the dynamic mechanical spectra of the samples can be compared in the glass transition region, and the timetemperature principle can be applied. The time-temperature superposition relationship is usually expected to hold only for thermo-rheologically simple materials. The composite systems under study with $20 \%$ of silica microparticles (by weight) are heterogeneous systems. However the DMA characterization performed on them did 
not suggest a multiphase structure. Therefore, although these materials are complex in composition and morphology, the simple relaxation behaviour of the composites as revealed by the DMA results led us to assume a "pseudo-homogeneous" structure for these samples to evaluate the "pseudo-viscoelastic properties" of the composites using the time-temperature superposition principle. This approximation has already been used for other complex systems such as polymer blends and even with ternary systems (thermotropic liquid crystalline polymer blends) [35]. Therefore, considering this, and as a kind of approximation, the time-temperature superposition principle can be applied to compute the Williams-Landel-Ferry (WLF) coefficients, $C_{1}^{\mathrm{g}}$ and $C_{2}^{\mathrm{g}}$, from equations (2) and (3), as a function of the network structure [36]:

$$
\begin{gathered}
\log a_{\mathrm{T}}=-\frac{C_{1}^{0}\left(T-T_{0}\right)}{C_{2}^{0}+T-T_{0}}, \\
C_{1}^{\mathrm{g}} C_{2}^{\mathrm{g}}=C_{1}^{0} C_{2}^{0} \text { and } T_{\mathrm{g}}(1 \mathrm{~Hz})-C_{2}^{\mathrm{g}}=T_{0}-C_{2}^{0},
\end{gathered}
$$

where $C_{1}^{0}$ and $C_{2}^{0}$ are the values of the viscoelastic coefficients at the reference temperature $T_{0}$ and $a_{\mathrm{T}}$ is the shift factor.

As an example, in Fig. 6 the data relative to the APTES system are illustrated. The shift factors $a_{\mathrm{T}}$ are usually obtained from the master curves (Fig. 7) built from the plots of $E^{\prime}$ versus frequency at different temperatures taking as the reference temperature, $T_{0}>T_{\mathrm{g}}\left(T_{0}=103^{\circ} \mathrm{C}\right.$ for the sample of Fig. 7). It can be observed in Fig. 7 that the superposition occurs over nearly the whole measured frequency

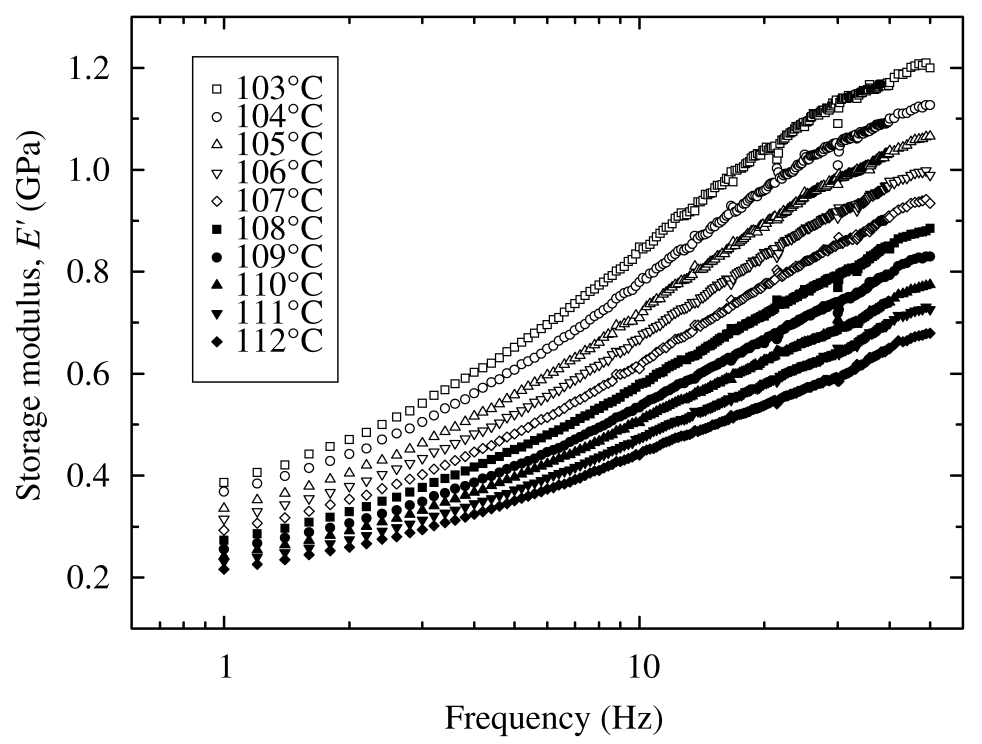

Figure 6. Storage modulus, $E^{\prime}$, variation as a function of frequency at different temperatures up to the $T_{\mathrm{g}}$ for the APTES sample. 


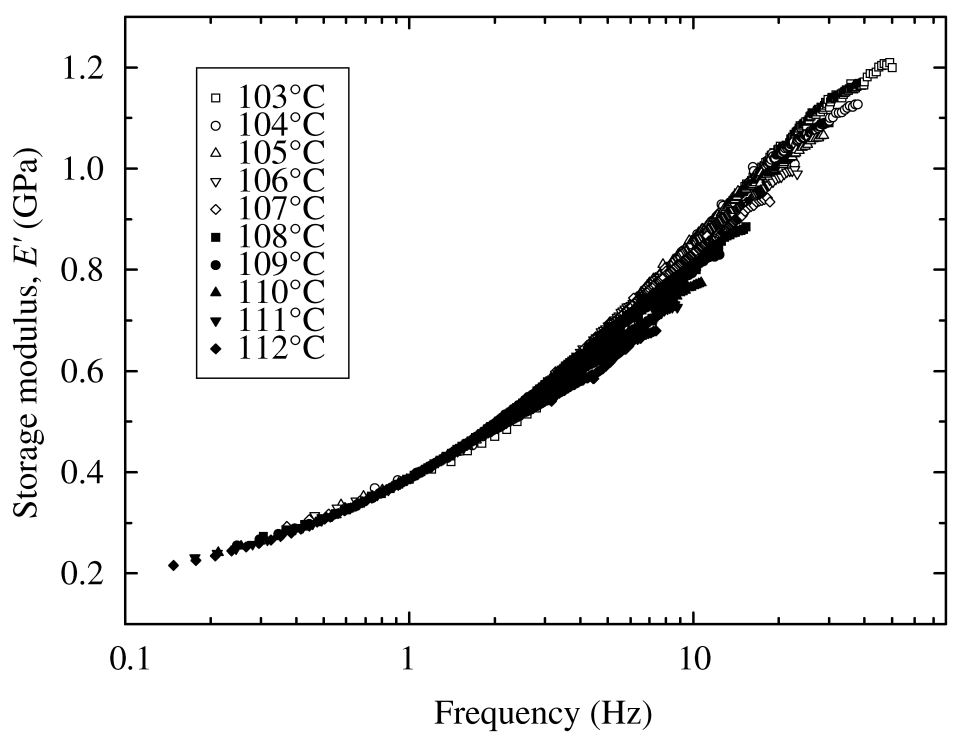

Figure 7. Master curve resulting from application of the shift factors to the curves plotted in Fig. 6.

Table 4.

WLF coefficients, pseudo free volume fraction $\left(f_{\mathrm{g}}\right)$, pseudo-thermal expansion coefficient $\left(\alpha_{\mathrm{f}}\right)$ and flexural properties of epoxy filled with treated and untreated silica

\begin{tabular}{lrllllll}
\hline Sample & $C_{1}^{\mathrm{g}}\left({ }^{\circ} \mathrm{C}\right)$ & $C_{2}^{\mathrm{g}}\left({ }^{\circ} \mathrm{C}\right)$ & $10^{2} f_{\mathrm{g}}$ & $10^{3} \cdot \alpha_{\mathrm{f}}$ & $\begin{array}{l}\text { Flexural modulus } \\
(\mathrm{GPa})\end{array}$ & $\begin{array}{l}\text { Yield stress } \\
(\mathrm{MPa})\end{array}$ & \multicolumn{1}{|c|}{$\begin{array}{l}\langle\mathrm{Area}\rangle^{1} \\
\left(\mu \mathrm{m}^{2}\right)\end{array}$} \\
\hline DGEBA & 8.4 & 49.3 & 5.2 & 2.0 & $2.9 \pm 0.1$ & - & \multicolumn{1}{|}{} \\
SILICA & 10.3 & 55.9 & 4.2 & 1.2 & $5.2 \pm 0.1$ & $91 \pm 12$ & $44.6(198)$ \\
APTES & 5.2 & 19.5 & 8.4 & 6.2 & $4.8 \pm 0.2$ & $77 \pm 5$ & $117.0(812)$ \\
APTES50 & 10.3 & 73.4 & 4.2 & 1.4 & $5.1 \pm 0.2$ & $90 \pm 6$ & $87.1(681)$ \\
APDES & 12.9 & 55.9 & 3.4 & 0.7 & $6.7 \pm 0.1$ & $113 \pm 9$ & $58.9(321)$
\end{tabular}

$C_{1}^{0}, C_{2}^{0}$ WLF coefficients, $f_{\mathrm{g}}$ : pseudo-free volume fraction; $\alpha_{\mathrm{f}}$, pseudo-thermal expansion coefficient. 〈Area〉: average area occupied by the reinforcement obtained from the image analysis of SEM micrographs.

${ }^{1}$ The numbers in parentheses correspond to the standard deviation. The high values obtained indicate that the particle size distribution does not follow a normal distribution, the number of big particles being very small, which broadens the distribution.

range. This superposition range corresponds to the region of slower dynamics, i.e., large segmental motion.

The values of the WLF coefficients obtained from the plots of $\left(T-T_{0}\right) / \log a_{\mathrm{T}}$ vs. $\left(T-T_{0}\right)$ for the different samples studied are listed in Table 4. Except for the DGEBA system, they are quite different from those obtained for epoxy resins cured with aliphatic diamines [37] confirming, therefore, that the introduction of the filler greatly modifies the viscoelastic behaviour with respect to the unfilled system. 
The "pseudo-free volume fraction", $f_{\mathrm{g}}$, and the pseudo-thermal expansion coefficients, $\alpha_{\mathrm{f}}$, at the $T_{\mathrm{g}}$, can be easily calculated from the relations of the viscoelastic coefficients with the free volume parameters [36] according to:

$$
C_{1}^{\mathrm{g}}=\frac{B}{2.3 f_{\mathrm{g}}} \quad \text { and } \quad C_{2}^{\mathrm{g}}=\frac{f_{\mathrm{g}}}{\alpha_{\mathrm{f}}},
$$

where $B$ is the Doolittle constant [36] which is commonly taken as 1 , and $\alpha_{\mathrm{f}}$ could be the pseudo-thermal expansion coefficient of the free volume. Filled systems consist of at least two phases, so, although one should be careful when interpreting $f_{\mathrm{g}}$ and $\alpha_{\mathrm{f}}$ results, it is proposed to compare results for materials of the same type.

In comparing the filled samples (Table 4), it is observed that the fractional free volume values at $T=T_{\mathrm{g}}$ are quite different for the studied materials, in contrast with the values of the $\alpha$-relaxation temperature and the rubbery modulus that are not very different for the coated systems. Differences in $f_{\mathrm{g}}$ cannot be explained in terms of the variations in the $B$ constant since the calculated values for $B$ range typically between 0.9 and 1.6. Moreover, the similarity in thermal properties and the lack of it in the free volume parameter can be understood if we take into account that $T_{\mathrm{g}}$, and $\tan \delta$ mainly inform about the bulk polymer while $f_{\mathrm{g}}$ (measured far from the rubbery plateau) informs about the molecular packing in the whole system (polymer + interphase + filler) but, of course, in the frequency range in which superposition occurs. Therefore, one might say that the higher the value of $f_{\mathrm{g}}$, the less the packed structure.

Values of $f_{\mathrm{g}}$ can be ordered in the following way: APDES $<$ SILICA $<$ APTES50 < APTES. Since superposition occurs in the slower dynamics regime near the $\alpha$-relaxation temperature and since the "pseudo-free volume fraction" at $T_{\mathrm{g}}$ becomes almost frozen at $T<T_{\mathrm{g}}$, it should be expected that packing-dependent mechanical properties should follow the same trend.

Flexural mechanical properties were measured for the studied systems and the results are presented in Table 4. It can be seen that there exists a good qualitative correlation between the room temperature yield stress and flexural modulus and the "pseudo-free volume" indicating that when the latter decreases the flexural yield stress and modulus increase. According to the classical Eyring theory of activated processes, yielding can be considered as the consequence of molecular flow induced by the applied stresses [38]. The Eyring equation for the yield stress predicts a reciprocal dependence of yield stress and the activation volume for plastic deformation at constant temperature and strain rate. There exists a similarity between this activation volume and the critical volume for the flow process as it appears in the classical Doolittle equation of viscosity of liquids [36] so it can be assumed that the activation volume for the plastic deformation should be proportional to the fractional free volume as observed in Table 4.

In Fig. 8 the SEM images corresponding to the fracture surfaces of the four filled composites are shown. It is observed that the silica particles mainly form agglomerates (white regions) with an average size highly dependent on the surface coating 


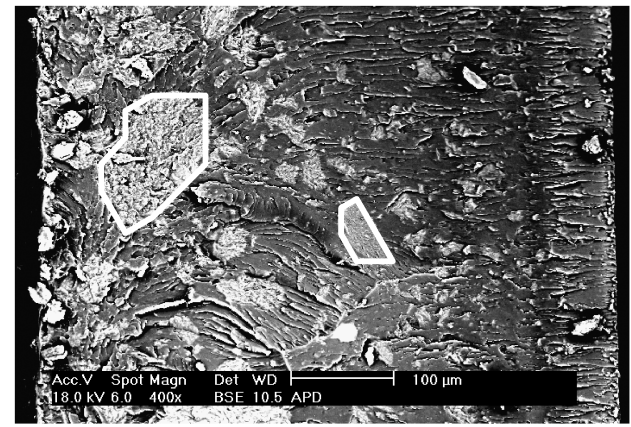

(a)

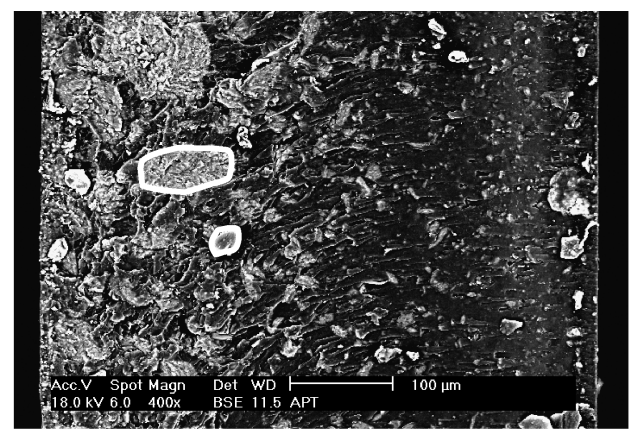

(c)

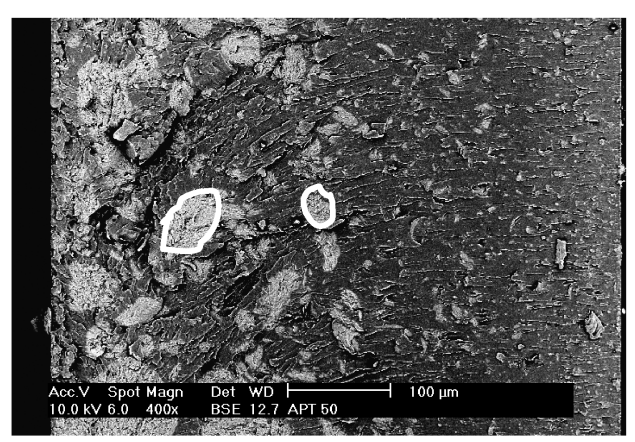

(b)

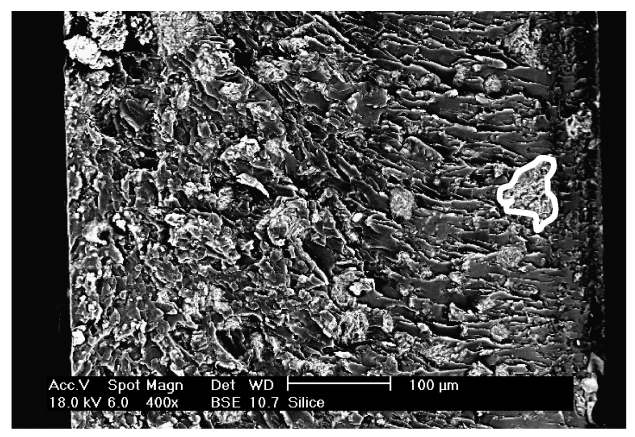

(d)

Figure 8. SEM images corresponding to the fracture surfaces of the four composites studied: (a) APDES; (b) APTES50; (c) APTES and (d) SILICA.

procedure. The results from the analysis of the particle size distribution are also listed in Table 4. Although the size distributions are very broad, the average aggregate area can be used to qualitatively compare the behaviour of the studied samples. For the surface coated particle composites, the average area and the standard deviation decrease in the following order APTES $>$ APTES50 $>$ APDES $>$ SILICA. It is interesting to note that yield stress and modulus follow opposite trends but, in the length scale of the aggregates, no clear correlation should exist between the size and the mechanical behaviour. The smallest aggregate area and the narrowest distribution correspond to the composite where the silica was not surface coated. These results can be explained considering the coating process with silanes. Prior to drying, the polysiloxane coating contains a large amount of silanol groups and un-hydrolyzed residues that may form inter-particle linkages in further steps, as it has been observed in silanized glass fibres [24, 39]. The aggregates formed by chemically bonded particles are very difficult to disperse even under high shearing conditions. When the particles are sheared with DGEBA an effective dispersion occurs only if DGEBA is able to penetrate the pores and the inter-particle regions. The trend found for the aggregate size suggests that the particles are better wetted by DGEBA as the content of silane is decreased. 


\section{Conclusions}

In this work the characterization of a silica filled epoxy composite and the effects of the particle distribution and the surface treatment on the thermo-mechanical and mechanical properties of the composites were analysed. The glass transition temperatures, $T_{\mathrm{g}}$, obtained for the studied samples reveal that both the filler as well as its surface treatment greatly affect the polymer structure in a composite material, at least under the curing conditions used. It seems that there is a stoichiometric change in the epoxy/amine mixture when it is filled with silica, which causes a decrease in the $T_{\mathrm{g}}$. Higher segmental mobility and more relaxing species were obtained for the DGEBA and SILICA samples. In the case of DGEBA sample this behaviour might be associated with its higher content of polymer, while for the SILICA sample it has been interpreted in terms of the off-stoichiometry induced by the large surface free energy.

While the reinforcing efficiency factor $\chi$ at the rubbery plateau has the same value independent of the coating structure, the "pseudo-fractional free volume", calculated from the superposition in the slow dynamics regime, seems to depend strongly on the type of coating. When the amount of chemically bonded silane is increased the fractional free volume increases also. The free volume parameter is related to the mechanical performance of the composites. A good qualitative correlation has been found between the latter and the yield stress. Finally, in the length scale of the aggregates, no clear correlation exists between the size and the mechanical behaviour.

\section{Acknowledgements}

Authors gratefully acknowledge projects Nanoter (MAT2001347), Interfases (S-0505/MAT/0227) and MEC, Acciones Integradas (HH2006-0007) for financial support. Furthermore, the authors acknowledge the Universidad Carlos III de Madrid and the Universidad del País Vasco/Euskal Herriko Unibertsitatea for supporting Dr. J. González-Benito at the Departamento de Ingeniería Química y del M. Ambiente.

\section{References}

1. P. L. Teh, M. Mariatti, H. M. Akil, C. K. Yeoh, K. N. Seetharamu, A. N. R. Wagiman and K. S. Beh, Mater. Lett. 61, 2156 (2007).

2. M. L. Sham and J. K. Kim, Composites Part A 35, 537 (2004).

3. S. Garoushi, P. K. Vallittu and L. V. J. Lassila, Dental Materials 24, 211 (2008).

4. M. H. Chen, C. R. Chen, S. H. Hsu, S. P. Sun and W. F. Su, Dental Materials 22, 138 (2006).

5. P. Wong and R. S. Bollampally, J. Appl. Polym. Sci. 74, 3396 (1999).

6. J. Lee and A. F. Yee, Polymer 41, 8363 (2000).

7. P. Bajaj, N. K. Jha and R. A. Kumar, J. Appl. Polym. Sci. 40, 203 (1990).

8. N. Altmann, P. J. Halley, J. Cooper-White and J. Lange, Macromol. Symp. 169, 171 (2001).

9. V. A. Tertykh, Macromol. Symp. 108, 55 (1996). 
10. F. Clement, A. Lapra, L. Bokobza, L. Monnerie and P. Ménez, Polymer 42, 6259 (2001).

11. T. Yasumasa and N. J. Makio, J. Chem. Eng. Jap. 33, 317 (2000).

12. B. Pukansky, Polypropylene: Structure, Blends and Composites. Chapman and Hall, London (1995).

13. R. Mülhaupt and F. Stricker, Kunstoffe-Plast Europe 87, 482 (1997).

14. E. P. Plueddemann, Silane Coupling Agents. Plenum Press, New York, NY (1982).

15. H. Hamada, N. Ikuta, N. Nishida and Z. Maekawa, Composites 25, 512 (1994).

16. K. L. Mittal (Ed.), Silanes and Other Coupling Agents, Vol. 4. VSP/Brill, Leiden (2007).

17. J. González-Benito, J. Colloid Interface Sci. 267, 326 (2003).

18. G. Van Assche and B. Van Mele, Polymer 43, 4605 (2002).

19. A. J. Aznar, E. Gutiérrez, P. Díaz, A. Alvarez and G. Poncelet, Microporous Mater. 6, 105 (1996).

20. A. J. Aznar, A. Álvarez, P. Díaz del Castillo, J. Coca and G. Poncelet, Patent No., P-9002483 (1990).

21. H. Ishida and J. L. Koenig, Polym. Eng. Sci. 18, 128 (1978).

22. C. Chiang, H. Ishida and J. L. Koenig, J. Colloid Interface Sci. 74, 396 (1980).

23. J. González-Benito, J. C. Cabanelas, A. J. Aznar, M. R. Vigil, J. Bravo and J. Baselga, J. Appl. Polym. Sci. 62, 375 (1996).

24. J. González-Benito, J. Baselga and A. J. Aznar, J. Mater. Process. Technol. 92-93, 129 (1999).

25. J. F. Gerard, J. Galy and J. P. Pascault, Polym. Eng. Sci. 31, 615 (1991).

26. J. Zhou and J. P. Lucas, Polymer 40, 5513 (1999).

27. C. Damian, E. Espuche and M. Escoubes, Polym. Degrad. Stabil. 72, 447 (2001).

28. I. McEwan, R. A. Pethrick and S. J. Shaw, Polymer 40, 4213 (1999).

29. L. E. Nielsen, Mechanical Properties of Polymers and Composites. Marcel Dekker, New York, NY (1974).

30. C. Salom, M. G. Prolongo, R. M. Masegosa, J. Baselga and A. Güemes, Eur. Polym. J. 28, 1135 (1992).

31. L. E. Nielsen, J. Macromol. Sci. C3, 69 (1969).

32. A. G. Facca, T. Kortschot and N. Yan, Composites: Part A 37, 1660 (2006).

33. R. F. Eduljee and R. L. McCullough, in: Elastic Properties of Composites, Structure and Properties of Composites, R. W. Cahn, P. Haasen and E. J. Kramer (Eds). VCH, Weinheim (1993).

34. J. W. Ashton, J. C. Halpin and P. H. Petit, Primer on Composite Materials: Analysis. Technomic, Lancaster, PA (1969).

35. E. Shivakumar, C. K. Das, E. Segal and M. Narkis, Polymer 46, 3363 (2005).

36. E. Riande, R. Díaz Calleja, M. G. Prolongo, R. M. Masegosa and C. Salom, Polymer Viscoelasticity. Marcel Dekker, New York, NY (2000).

37. D. H. Kaelble, in: Epoxy Resins, C. A. May and Y. Tanaka (Eds). Marcel Dekker, New York, NY (1973).

38. I. M. Ward, Mechanical Properties of Solid Polymers. Wiley, Wiltshire, UK (1990).

39. A. El Achari, A. Ghenain, C. Caze, V. Wolff and E. Carlier, Textile Res. J. 66, 483 (1996). 